\title{
Study of diffusion and related phenomena by electron probe microanalyser
}

\author{
K BHANUMURTHY* and G B KALE \\ Materials Science Division, Bhabha Atomic Research Centre, Mumbai 400085 , India
}

\begin{abstract}
Interaction of various materials at high temperatures leads to the formation of reaction zones of differing nature ranging from simple solid solutions to multiphase structures. Understanding the diffusion processes leading to the formation of reaction zone and its nature requires an accurate estimation of composition and the distribution of the phases formed. Electron probe microanalyser (EPMA) is an indispensable technique for this purpose, where the quantitative analysis of micron sized layers formed in the diffusion zone is required. Application of EPMA to study the diffusion processes in several metallic systems is dealt in detail. Utility of this technique to study problems related to contact metallurgy in semiconductors and practical problems of joining, particularly to that of diffusion bonding, is ako deseribed in this paper.
\end{abstract}

Keywords. Diffusion reaction; EPMA; diffusion coefficient; interdiffusion; diffusion bonding.

\section{Introduction}

Electron probe microanalyser (EPMA) is being extensively used in variety of fields including, metallurgy, ceramics, electronics, biology, mineralogy, medicine and geology. Applications related to metallurgy and materials science are essentially, the analysis of inclusions and precipitates, phase identification, phase diagram evaluation, crystallographic studies, fractography and failure analysis and diffusion research. Extensive work related to industrial application of EPMA includes new alloy development, texture studies in steel industry and quality control. EPMA provides unique way to identify localized fine scale structure $(>1 \mu \mathrm{m})$ and provide information related to quantitative chemistry associated with it. It has contributed significantly in the last three decades in the development of a vast knowledge related to the chemical diffusion in metals and alloys. These studies include interdiffusion in binary, ternary and multicomponent systems, compatibility studies particularly related to nuclear fuel/cladding, interface reactions in metal-ceramic and ceramic-ceramic composites and also in characterizing the reaction zone formed during several joining techniques like soldering, brazing, welding and diffusion bonding. These studies provided an enormous literature leading to the evaluation of diffusion parameters like diffusion coefficient $(D)$, frequency factor $\left(D_{11}\right)$, activation energy $(Q)$ and several parameters related to layer growth kinetics.

\footnotetext{
*Author for correspondence
}

\section{Electron probe microanalyser}

The basis of this technique lies in the emission of X-rays from the surface of a material exposed to the primary beam of electrons of energy range $10-50 \mathrm{keV}$. A portion of these X-rays is related to the energies of the characteristic of the atom from which they originate. The energy of the $\mathrm{X}$-ray emission is measured by the wavelength dispersive spectrometer (WDS) and/or solid state energy dispersive spectrometer (EDX) with the detectors positioned around the periphery of the microanalytical stage. In addition, scanning electron microscopy (SEM) also forms a part of an integrated EPMA to accurately position the details to be probed by EPMA. Excellent review articles on the working, development and applications are available in literature (Heinrich and Newbury 1991; Cahn et al 1993). A detailed working principle of this equipment is shown in figure 1.

Quantitative analysis concerns with the conversion of the X-ray intensity data measured on the samples and the standards to chemical compositions. Extensive research work has been reported in the literature and several schemes have been proposed for quantitative analysis. Standardless analysis, semiemperical methods, the conventional ZAF method and the analysis based on the calculated $\phi(\rho z)$ curves which are effective for the analysis of low atomic numbers are some of the typical correction methods used. Recent developments include the analysis of thin films, where the electron penetration is greater than the thickness of the sample and the relatively new method of Pouchou, Pichoir and Packwood (PAP) is based on the modified $\phi(\rho z)$ curves for the analysis of the surface layers (Cahn et al 1993). 
The basic requirement of the exact quantitative analysis involves (i) accurate positioning of the sample and the standard and its flatness to the electron beam, (ii) confirmation that the $\mathrm{X}$-rays are generated and observed in the phase of interest, (iii) optimization of the operating parameters, (iv) information regarding the accuracy of the take off angle $(\psi)$, (v) large counting statistics and (vi) accurate measurement of the peak above the background. It is very difficult to get all the required information and also satisfy these conditions. In general, the elemental sensitivity is order of $100 \mathrm{ppm}$ for WDS analysis and about $1000 \mathrm{ppm}$ for EDS. Analysis can be generally performed in a spot mode at $(1 \mu \mathrm{m})^{3}$ analysed volume or a line profile or in a two-dimensional elemental distribution map. Though EPMA is an extremely powerful technique for studying materials, it requires several techniques like TEM with analytical capability, EELS in conjunction for analysing features whose dimensions are smaller than $1 \mu \mathrm{m}$.

\section{Diffusion studies by EPMA}

When the different materials are kept in contact at higher temperatures, they diffuse into each other and depth of diffusion is dependent on the diffusivities of the species and the time of annealing. Diffusion takes place down the activity gradient and Fick's second law is generally used to estimate the diffusion coefficients.

Measurements of diffusion coefficients is based basically on two concepts: (I) Measurement of diffusion length: These studies involve long range diffusion where displacements are more than the interatomic distances, ' $d$ ' $\left.\left[\left\langle X^{2}\right\rangle^{1 / 2}\right\rangle d\right]$. Based on the measurements of the displacement $\Delta X$, diffusion flux $(J)$, and concentration profile $C(x, y, z, t)$ diffusion coefficient are evaluated. The type of diffusion coefficient measured could be self, impurity or chemical diffusion depending on the technique

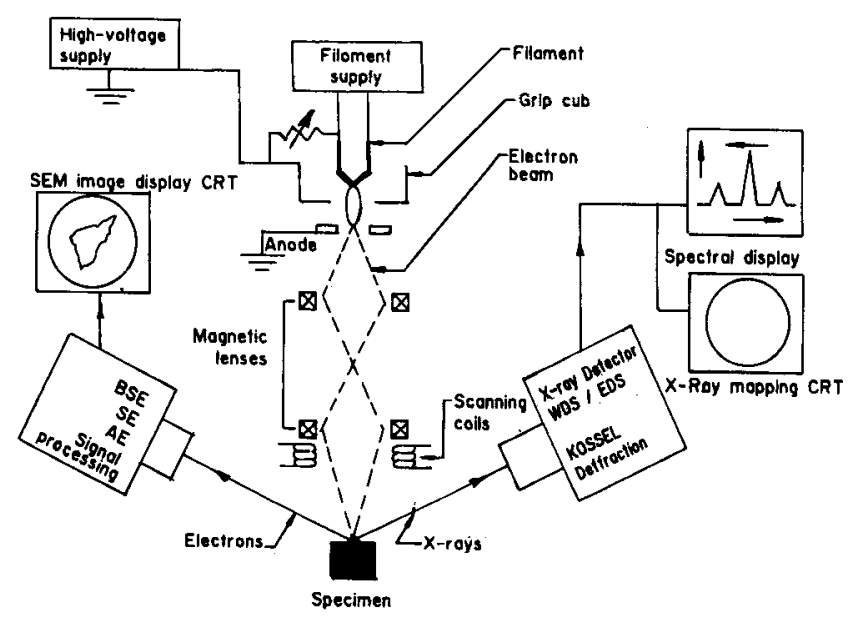

Figure 1. Block diagram of the working principle of EPMA. used and (II) Measurement of relaxation phenomena: These studies essentially depend on the measurement of relaxation time of one or more diffusing species. The diffusion coefficient is derived based on this data with a suitable model relevant to the technique. Mostly self diffusion coefficients are measured by these techniques.

Various techniques are available to measure the values of diffusion coefficients. Comparison of these techniques along with their limitations are listed in table 1 . It can be seen clearly in the table that EPMA has only spatial resolution of $1-2 \mu \mathrm{m}$ which will yield a diffusion coefficient in the range of $10^{-12}-10^{-16} \mathrm{~m}^{2} / \mathrm{sec}$. However, if one needs a better estimate it is essential to use complimentary technique where spatial resolution is better than 1-2 $\mu \mathrm{m}$. It should be emphasized that EPMA unlike AES or SIMS is non-destructive technique. Moreover, several diffusion controlled processes in metals and alloys are generally high temperature phenomena, where displacements are more than $1-2 \mu \mathrm{m}$. EPMA is a powerful technique to study these displacements. A detailed description of these processes is mentioned below.

\subsection{Diffusion coefficients in materials}

In general, in multicomponent system with ' $n$ ' components the species diffuse into each other and flux of the component depends not only on its own concentration gradient but also on the concentration gradients of all other components. The Onsager equation of flux can be written as (Onsager 1945)

$$
J_{\mathrm{i}}=\sum_{j=1}^{n-1}-D_{i j}^{n}\left(\frac{\mathrm{d} C_{j}}{\mathrm{~d} x}\right),
$$

where $D_{i j}$ is diffusion coefficient and $\mathrm{d} C_{j} / \mathrm{d} x$ concentration gradient of the $j$ th component.

These diffusivities are called intrinsic diffusivities and such $n(n-1)$ diffusion coefficients have to be defined. These diffusivities are with respect to the lattice fixed frame of reference which is itself moving with respect to laboratory frame of reference. Diffusion coefficients measured with respect to laboratory fixed frame of reference are called interdiffusion coefficients and there are such $(n-1)^{2}$ diffusion coefficients to be defined to describe the system completely.

Experimentally impurity diffusion coefficients are measured by allowing the species to diffuse into the matrix. EPMA can be used to measure concentration of diffusing species as a function of distance. EPMA, though has a low spatial resolution can be effectively used for measuring concentration profiles including those for light elements. In these cases diffusion coefficient is independent of composition and error function method is generally used to evaluate it. Recently, the diffusion of 
nitrogen in welds of steel has been studied by EPMA (Kucera et al 1994).

Chemical diffusion coefficients are measured under the influence of concentration gradient. In this case, two alloys of ' $n$ ' components are annealed at elevated temperature for sufficient time to allow diffusion to occur. The resulting concentration profile is established by EPMA. Diffusion coefficients are evaluated from the experimental profile. Experimental determination of $D$ values for binary, ternary and higher order systems are described below.

3.1a Binary systems: Simplest of ' $n$ ' component systems is binary system. The concentration profiles across the diffusion zone can be established with the help of EPMA. Interdiffusion coefficients are evaluated by using Boltzmann-Matano method (Boltzmann 1894, Matano 1933) which is a solution of (1):

$$
\tilde{D}\left(C^{\prime}\right)=-\frac{1}{2 t}\left(\frac{\mathrm{d} x}{\mathrm{~d} C}\right) \int_{0}^{C} x \mathrm{~d} C
$$

where $D\left(C^{\prime}\right)$ is diffusion coefficient at composition $C^{\prime}, t$ is time of annealing and $(\mathrm{d} C / \mathrm{d} x)_{C^{\prime}}$ is concentration gradient at $C=C^{\prime}$ and $\int_{0}^{C^{\prime}} x \mathrm{~d} C$ is area under the curve up to Matano interface.

This method assumes that molar volume of the system remains constant. Interdiffusion studies in Ti-Mo system have been carried out recently (Kale and Patil 1994). In Ti-Mo system it is found that at any plane in the diffusion zone no molar volume change is involved and hence Boltzman-Matano has been used to estimate $D$ values. A more rigorous method for evaluation of diffusion coefficients in systems involving variable molar volume $V_{\mathrm{m}}$ upon mixing was suggested by Sauer and Frecise (1962). The method does not need the explicit calculation of position of Matano interface.

Binary systems with restricted solubility result in the formation of intermetallic compounds in the diffusion zone. The phases grow in the diffusion zone as sequence of layers. Boltzmann Matano method was modified by Heumann (1962) to evaluate average diffusion coefficients of the phase. This method is not useful for the determination of $D$ for the phases with narrow homogeneity range or for line compounds. Moreover, the phases sometimes grow with incubation period or some phases grow at the expense of others and hence establishing proper Matano interface is difficult. Sauer and Frecise method, which does not need explicit calculation of Matano interface to evaluate $D$ was modified by Wagner (1969). This method is useful for the evaluation of diffusion coefficients for line compounds. Recent studies on $\mathrm{Ni}-\mathrm{Zr}$ system have indicated that the evaluation of diffusion coefficients by both these methods are comparable (Bhanumurthy et al 1990).

3.1b Ternary and higher component systems: As seen from (1) there are $(n-1)$ unknowns in equation and as such we need $(n-1)$ independent simultaneous equations to evaluate these unknowns. Typically, in a ternary system we need two independent diffusion profiles which have common concentration at which only diffusion coefficients can be calculated. In order to evaluate dif-

Table 1. Values of diffusion coefficients accessible to different techniques and comparison of various diffusion measuring techniques.

\begin{tabular}{|c|c|c|c|c|}
\hline \multicolumn{3}{|c|}{ Traditional methods } & \multicolumn{2}{|c|}{ Non-traditional methods } \\
\hline Technique & $\begin{array}{l}\text { Displacement } \\
(\Delta X, \mathrm{~m})\end{array}$ & $\begin{array}{c}D \\
\left(\mathrm{~m}^{2} / \mathrm{sec}\right)\end{array}$ & Technique & $\begin{array}{c}D \\
\left(\mathrm{~m}^{2} / \mathrm{sec}\right)\end{array}$ \\
\hline $\begin{array}{l}\text { Lathe sectioning and } \\
\text { grinding }\end{array}$ & $0.1-250 \times 10^{-6}$ & $10^{-19}-10^{-6}$ & Nuclear magnetic resonance & $10^{-20}-10^{-9}$ \\
\hline Microtome sectioning & $1-10 \times 10^{-6}$ & $10^{-17}-10^{-12}$ & Neutron elastic scattering & $10^{-11}-10^{-9}$ \\
\hline Chemical etching & $10 \times 10^{-6}$ & $10^{-15}-10^{-13}$ & Mossbaur effect & $10^{-15}-10^{-11}$ \\
\hline Electrochemical etching & $50 \times 10^{-9}$ & $10^{-20}-10^{-17}$ & Conductivity & $10^{-17}-10^{-10}$ \\
\hline $\begin{array}{l}\text { Sputtering (auger electron } \\
\text { spectroscopy) }\end{array}$ & $5-100 \times 10^{-9}$ & $10^{-22}-10^{-17}$ & $\begin{array}{l}\text { Resistivity } \\
\text { (semiconductors) }\end{array}$ & $10^{-20}-10^{-12}$ \\
\hline $\begin{array}{l}\text { EPMA (electron probe } \\
\text { microanalyser) }\end{array}$ & $1-2 \times 10^{-6}$ & $10^{-16}-10^{-12}$ & Internal friction & $10^{-20}-10^{-15}$ \\
\hline $\begin{array}{l}\text { SIMS (secondary ion mass } \\
\text { spectroscopy) }\end{array}$ & $1-100 \times 10^{-9}$ & $10^{-23}-10^{-17}$ & Magnetic anisotropy & $10^{-25}-10^{-21}$ \\
\hline $\begin{array}{l}\text { RBS (Rutherford back } \\
\text { scattering) }\end{array}$ & $1-50 \times 10^{-9}$ & $10^{-20}-10^{-17}$ & & \\
\hline
\end{tabular}


fusion coefficients at other compositions, other combinations of couples are needed to be made. Apart from this, diffusion paths are generally not linear and it is difficult to predict and plan the experiments. There is also a possibility of development of zero flux planes which cause the reversal of the flux in the diffusion zone. This requires cautious planning of experiments and also careful analysis by EPMA. Ternary diffusion in $\mathrm{Fe}-\mathrm{Cr}-\mathrm{Ni}$ system has been studied (Kale et al 1991). The isotherm at $1223 \mathrm{~K}$ and intersecting diffusion paths are shown in figure 2. Evaluation of diffusion coefficients in quaternary system by Boltzmann-Matano method and difficulties in its evaluation have been described (Heanley and Dayananda 1986). Average effective interdiffusion coefficient and integrated diffusion coefficient for systems involving higher orders have been defined (Dayananda 1996). Recently, effective diffusion coefficients in multicomponent system, Ti/stainless steel, have been evaluated (Kale et al 1998). The diffusion coefficients for $\mathrm{Ti}, \mathrm{Fe}$, $\mathrm{Ni}, \mathrm{Cr}$ have been evaluated using Boltzmann-Matano method from these profiles assuming binary system of $\mathrm{Fe}, \mathrm{Ni}$ and $\mathrm{G}$ with $\mathrm{Ti}$. The activation energy for diffusion coefficients of these elements have been evaluated and composition of the plane which controls the total diffusion processes has been established. This simple procedure is helpful in practical problems like diffusion bonding.

\section{Diffusion related phenomena}

There are large number of processes which are controlled by diffusion. Most of the phase transformations are

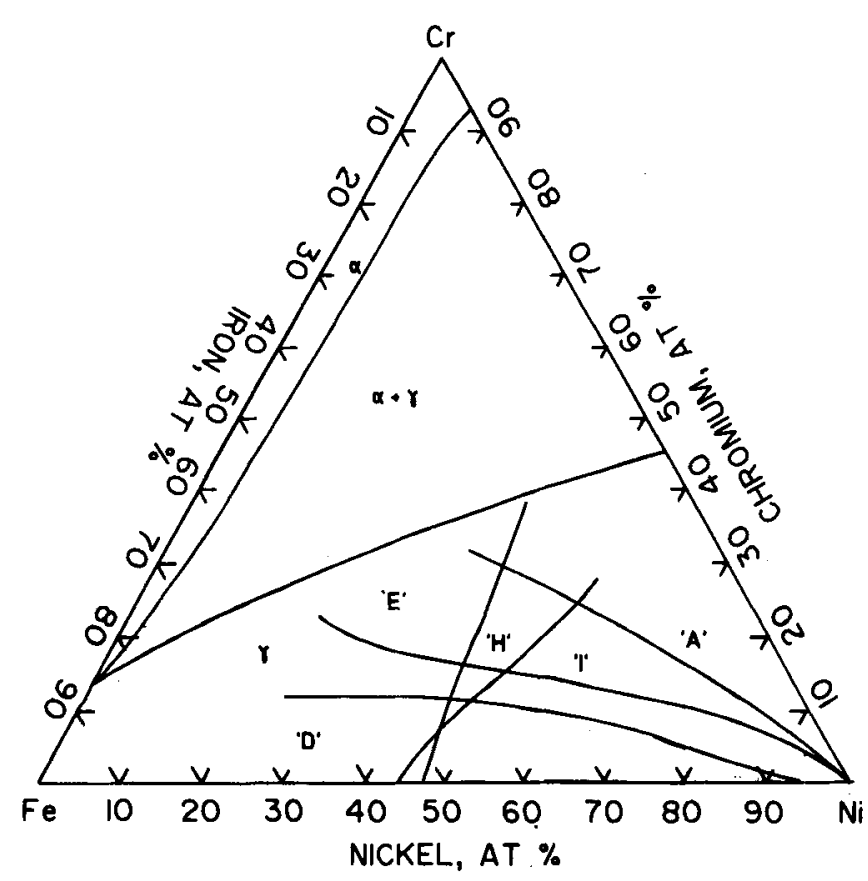

Figure 2. Phase diagram of $\mathrm{Fe}-\mathrm{Cr}-\mathrm{Ni}$ at $1223 \mathrm{~K}$ and the diffusion paths for various couples. governed by diffusion kinetics. Apart from phase transformation, plastic deformation at high temperature, creep, occur by diffusion essentially due to the movement of lattice defects. Oxidation, carburization, nitriding, sintering, coating, cladding and joining are generally used industrial processes which are possible due to diffusion. In addition, contact metallurgy related to metallic contacts to semiconductor compounds is another diffusion controlled process. In all these processes reactive diffusion between different materials takes place. Basic understanding of reactive diffusion is very important and detailed knowledge of this can be used for controlling these processes. Diffusion bonding is an important method of joining and requires an extensive knowledge of diffusion parameters and also the basic information on the phase formation. Use of EPMA in the study of reactive diffusion, understanding metallic contacts in compound semiconductors and its use in characterizing the reaction zone in diffusion bonded assemblies is discussed below.

\subsection{Reactive diffusion}

In reactive diffusion, two metals/alloys diffuse into each other, resulting in the formation of intermediate phases in the reaction zone. In principle, all the phases predicted by the phase diagram should form in the diffusion zone. But in practice, it is observed that, even for a simple system like binary system, not all the phases appear in the diffusion zone. Many a times, metastable/nonequilibrium (Philibert 1989), or glassy (Johnson 1986) phases appear. It has also been observed that some phases appear after a incubation time or disappear at higher temperature (Bhanumurthy et al 1990). The total nature of diffusion zone depends upon the temperature and time of annealing and also on nature of intermediate phases. The constitution of reaction zone with respect to formation, absence or disappearance of phases have been the subject of interest of many researches (Van Loo 1990; Kale 1995). In spite of extensive work there seem to be many open questions which need to be resolved (Philibert 1997).

Formation of a phase in diffusion zone is controlled by nucleation and growth processes. These processes are essentially governed by thermodynamic and kinetic considerations prevailing in the diffusion zone. Some of these aspects are discussed in detail (Philibert 1997). Several research workers (Walser and Bene 1976; Pretorious et al 1993; Bhanumurthy et al 1995) have also proposed many theoretical models to predict which phase will nucleate first. Recently, Pretorious model (Pretorious et al 1993) has been modified by incorporating congruency factor (Bhanumurthy et al 1995). This model predicts correctly the formation of first phase in the diffusion zone in several systems. 
4.1a Analysis of reaction zone by EPMA: The formation of intermetallic compounds of narrow width in the diffusion zone generally involves steep concentration gradients. It is also possible that there could be deviations in the phase compositions of the compounds compared to the equilibrium values. It is difficult to measure reliable concentration values at a distance smaller than $2 \mu \mathrm{m}$ from the interface. Some of these problems and the inherent difficulties involved in the correction procedure to arrive at the compositions of a phase, is illustrated in the $\mathrm{Ti}-\mathrm{Fe}$ and $\mathrm{Zr}-\mathrm{Ni}$ : In addition, these systems have been chosen as they illustrate interesting results associated with reactive diffusion.

4.1b Interdiffusion studies in Ti-Fe system: Interdiffusion in Ti-Fe system has been studied (Kale et al 1980). The equilibrium phase diagram of system depicts two phases viz. TiFe and $\mathrm{TiFe}_{2}$. However, experimental results indicate that none of the phases form in the diffusion zone for the couples annealed for all temperatures in which $\mathrm{Fe}$ is in $\gamma$ regime. Whereas, the couple annealed in lower temperatures in which $\mathrm{Fe}$ is in the $\alpha$ regime shows the formation of $\mathrm{TiFe}_{2}$ phase in the diffusion zone. Based on flux calculations (see table 2), it was inferred that the phases would not grow even after nucleation, due to unfavourable flux balance. The validity of these calculations were confirmed experimentally (Hirano and Iijima 1984).

4.1c Interdiffusion studies in $\mathrm{Zr}-\mathrm{Ni}$ system: The multiphase diffusion in $\mathrm{Zr}-\mathrm{Ni}$ has been studied (Bhanumurthy et al 1990). A typical concentration profile for the couple annealed at $1169 \mathrm{~K}$ is shown in figure 3. It is observed that $\mathrm{Ni}_{7} \mathrm{Zr}_{2}$ and $\mathrm{Ni}_{10} \mathrm{Zr}_{7}$ disappear above $1169 \mathrm{~K}$. Flux balance across the phase is probably responsible for the disappearance of the earlier formed phases at higher temperatures. Assuming that flux is directly proportional to diffusivities, the ratio of these diffusivities with adjoining phases are given in table 3 . It is seen from the table that diffusivitiy ratios for these phases decrease gradually with increase in temperature, indicating the tendency to disappear at higher temperatures.

Table 2. Flux of $\mathrm{Fe}$ atoms in $\mathrm{Fe}-\mathrm{Ti}$ system.

\begin{tabular}{lcccc}
\hline & & & \multicolumn{2}{c}{ Flux $J_{i}\left(\right.$ atoms $\left./ \mathrm{m}^{2} / \mathrm{sec}\right)$} \\
\cline { 4 - 5 } Couple & \multirow{2}{*}{$\begin{array}{c}\text { Temperature } \\
(\mathrm{K})\end{array}$} & Phase & Entering & Leaving \\
\hline & & & & \\
$\gamma \mathrm{Fe}-\beta \mathrm{Ti}$ & $>1100$ & $\mathrm{TiFe}_{2}$ & $8.4 \times 10^{10}$ & $1.4 \times 10^{12}$ \\
& & $\mathrm{TiFe}$ & $1.4 \times 10^{12}$ & $2.0 \times 10^{14}$ \\
$\alpha \mathrm{Fe}-\mathrm{TiFe}$ & $<1100$ & $\mathrm{TiFe}_{2}$ & $1.5 \times 10^{10}$ & $2.9 \times 10^{7}$ \\
\hline
\end{tabular}

\subsection{Diffusion reactions in ternary systems and} relevance to contact metallurgy

The development of metallic contacts to compound semiconductors like $6 \mathrm{H}-\mathrm{SiC}$, which are stable at high temperatures is an essential step in the ongoing miniaturization of high power electronic devices. Diffusion reaction between $\mathrm{SiC}$ and various other metals are of vital importance in the development of ohmic and Schottky contacts. In multiphase ternary systems, there is no unique way in which prediction can be made regarding the diffusion path. In general, detailed experiments are essential to have a knowledge of sequence of formation of these phases in the diffusion zone (Van Loo 1990). Based on the detailed experimentation and

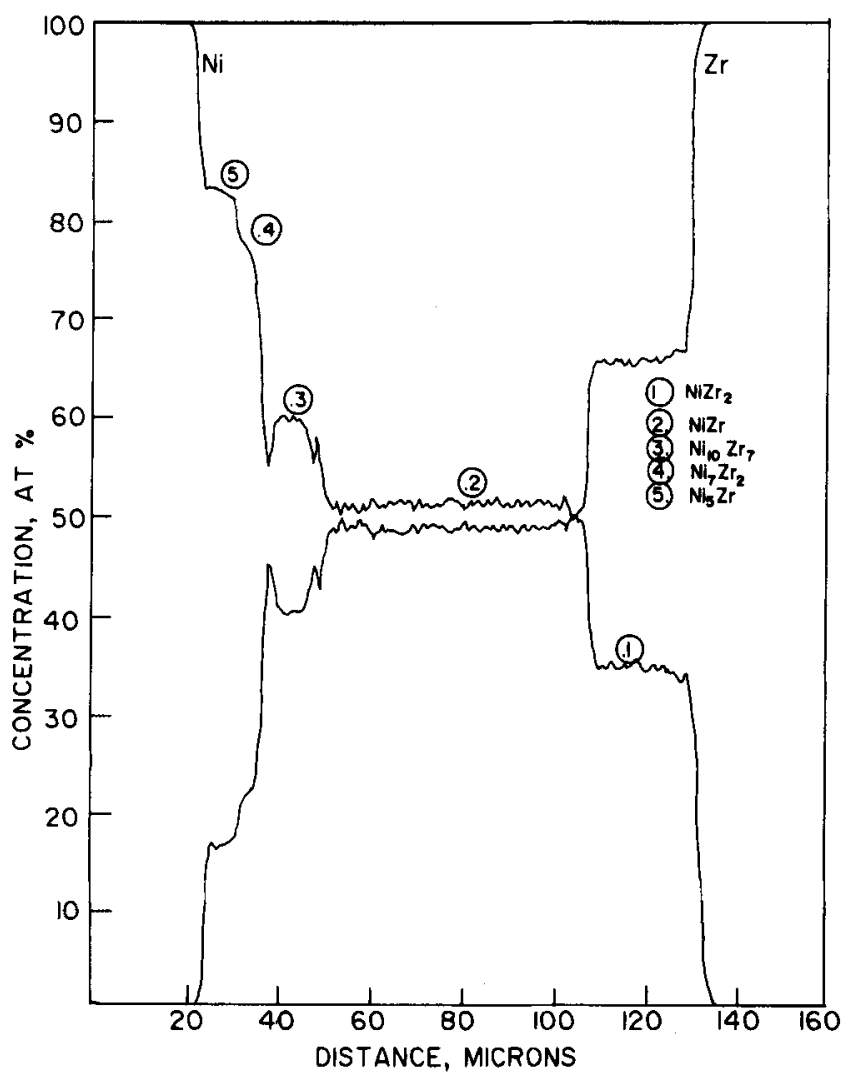

Figure 3. Concentration profiles of $\mathrm{Zr}$ and $\mathrm{Ni}$ for the diffusion couple $\mathrm{Ni} / \mathrm{Zr}$ annealed at $1169 \mathrm{~K}$ for $24 \mathrm{~h}$.

Table 3. Diffusivity ratios for intermediate phases to their adjoining phase in $\mathrm{Zr}-\mathrm{Ni}$ systems.

\begin{tabular}{lcc}
\hline Temperature (K) & $\mathrm{Ni}_{7} \mathrm{Zr}_{2}$ & $\mathrm{Ni}_{10} \mathrm{Zr}_{7}$ \\
\hline 1046 & $3 \cdot 0$ & 4.17 \\
1115 & $2 \cdot 5$ & 3.85 \\
1133 & $2 \cdot 33$ & 3.03 \\
1169 & $2 \cdot 14$ & 2.86 \\
\hline
\end{tabular}


thermodynamic stability, the necessary inputs for the contact on $6 \mathrm{H}-\mathrm{SiC}$ could be arrived. Diffusion reactions of $\mathrm{Ni}, \mathrm{W}, \mathrm{Cr}, \mathrm{Pd}$ and $\mathrm{Ti}$ with $6 \mathrm{H}-\mathrm{SiC}$ have been investigated (Goessmann and Schmid-Fetzer 1995, Bhanumurthy and Schmid-Fetzer 1996a). These studies confirmed that phase diagrams, diffusion reactions and electrical properties together will lead to the clear understanding of the metal/semiconductor contact formation.

Recently new class of microstructures involving the formation of periodic bands have been reported in many ternary systems (Kao and Chang 1993). The isotherm and diffusion path for the couple $6 \mathrm{H}-\mathrm{SiC} / \mathrm{Ni}$ annealed at $102 \mathrm{~K}$ for $24 \mathrm{~h}$ is shown in figure 4 . Analysis of $\mathrm{Si}$, $\mathrm{Ni}$ and particularly $\mathrm{C}$ by EPMA in these layers whose thickness is small is very difficult. Several models based on diffusion theory are put forward to satisfactorily explain these phenomena (Kao and Chang 1993). A comparison of these models along with the suggestion that a continuous joining pressure may be required to produce the periodic bands is published recently (Bhanumurthy and Schmid-Fetzer 1996b). However, it is still unclear which model is appropriate to explain all aspects of periodic layer formation.

\subsection{Diffusion bonding}

The information regarding the extent of interdiffusion, dilution and mixing of the phases is prerequisite to optimize the process parameters in several joining techniques like welding, brazing or diffusion bonding. EPMA with its unique capabilities has become an indispensable tool for characterizing the reaction zone formed due to any of the joining techniques. Specific examples related

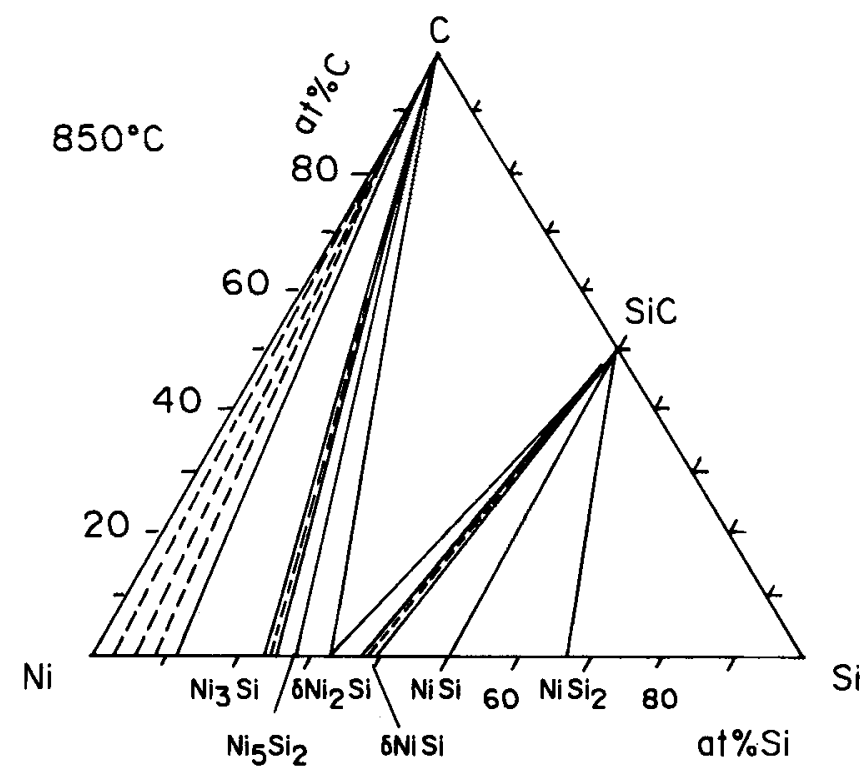

Figure 4. Phase diagram of $\mathrm{Si}-\mathrm{C}-\mathrm{Ni}$ and the diffusion path for the couple $6 \mathrm{H}-\mathrm{SiC} / \mathrm{Ni}$ annealed at $102 \mathrm{~K}$ for $24 \mathrm{~h}$. to joining of alloys and ceramic materials by diffusion bonding are discussed below.

4.3a Diffusion bonding of zircaloy-2 to stainless steel: Recently joining of zircaloy-2 $(\mathrm{Zr}-2)$ to stainless steel by diffusion bonding has been undertaken at the authors laboratory (Bhanumurthy et al 1994). The joining of these materials by conventional welding is undesirable because of the formation of intermetallic compounds like $\mathrm{FeZr}_{2}$ and $\mathrm{FeZr}_{3}$. Several intermediate layers consisting of $\mathrm{Zr}-2 / \mathrm{Nb} / \mathrm{Cu} / \mathrm{Ni} / \mathrm{stainless}$ steel have been used to prevent the formation of intermetallic compounds and also minimize the thermal expansion mismatch. Actual assembly of these specimens made by both solid state bonding and also by transient eutectic liquid phase bonding is shown in figure 5 .

4.3b Solid state bonding of HIP-SiC: Direct bonding of HiP-SiC generally requires high temperature above $1773 \mathrm{~K}$ and high pressure. The bonding between $\mathrm{SiC}$ is achieved in two stages (Bhanumurthy and Schmid-Fetzer 1996c), (i) the pressureless prereacting of the $\mathrm{SiC}$ pieces in a bed of $\mathrm{Cr}$ at $1273 \mathrm{~K}$ for $3 \mathrm{~h}$ to produce the required ternary phase $\left(\mathrm{Cr}_{5} \mathrm{Si}_{3} \mathrm{C}\right)$ on the $\mathrm{SiC}$ surface and (ii) diffusion bonding of the phases using $\mathrm{Ni}$ as an intermediate layer at $1213 \mathrm{~K}$ for $3 \mathrm{~h}$ at a pressure of $15 \mathrm{MPa}$. A typical back scattered electron image is shown in figure 6. Based on the extent of the reaction zone, optimization of process parameters have been carried out.

\section{Conclusions}

Study of diffusion reaction needs accurate estimation of composition of the phases nucleated and grown in the

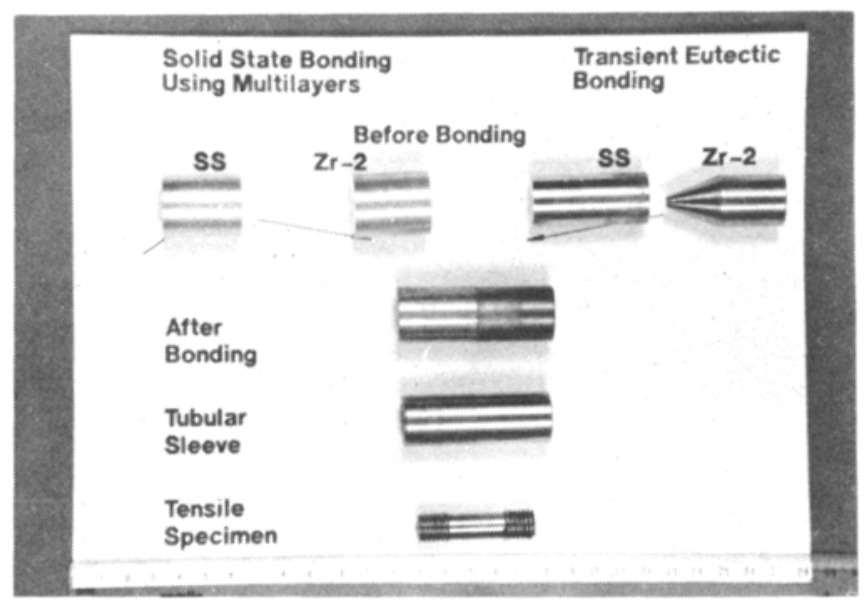

Figure 5. Details of the zircaloy-2/stainless steel specimens fabricated by solid state bonding and transient eutectic phase bonding along with tubular sleeves and tensile specimen. 


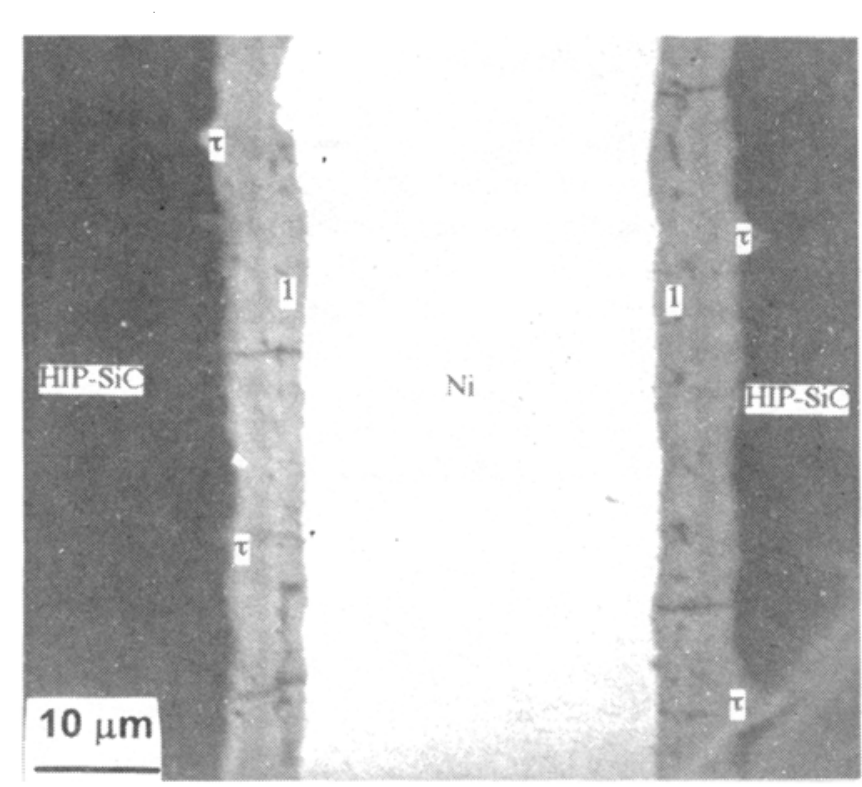

Figure 6. Back scattered electron image of cross section of the diffusion bonded specimen annealed at $1213 \mathrm{~K}$ for $3 \mathrm{~h}$. $\left(\tau=\mathrm{Cr}_{5} \mathrm{Si}_{3} \mathrm{C}\right.$ and $\mathrm{l}=\mathrm{Cr}_{23} \mathrm{C}_{6}$ ).

reaction zone. The evaluation of the diffusion coefficients requires the variation of the composition along the diffusion length. Several diffusion controlled processes in metals and alloys at high temperatures involve mass transfer in a dimension more than 1-2 $\mu \mathrm{m}$. EPMA is an indispensable technique to study these reactions and to analyse the reaction products. The use of this technique for evaluating the diffusion parameters in binary and higher order systems are illustrated in this paper. The utility of EPMA for studies of practical importance such as diffusion bonding and reactive diffusion in contact metallurgy has been discussed.

\section{Acknowledgements}

The authors wish to thank $\operatorname{Dr} S$ Banerjee, Associate Director, Materials Group and Professor R Schmid-Fetzer, Department of Metallurgical Engineering, Technical University of Clausthal, Clausthal, Germany for many useful discussions. One of the authors (KB) wishes to acknowledge Alexander von Humboldt Foundation for the financial support to carry out some of the work reported in this paper.

\section{References}

Bhanumurthy K and Schmid-Fetzer R 1996a Z Metallkde 8761 Bhanumurthy K and Schmid-Fetzer R 1996b Z. Metallkde 87 244

Bhanumurthy K and Schmid-Fetzer R 1996c Mater. Sci. Engg. 22035

Bhanumurthy K, Kale G B, Khera S K and Asundi M K 1990 Metall. Trans. A21 2897

Bhanumurthy K, Krishnan J, Kale G B and Banerjee S 1994 J. Nucl. Mater. 21767

Bhanumurthy K, Kale G B and Garg S P 1995 Trans. IIM 48 193

Boltzmann L 1894 Ann. Phys. 53960

Cahn R W, Haasen P and Kramer E J (eds) 1993 Materials science and technology-A comprehensive treatment (ed.) E Lifshin (Weinheim: VCH Verlagsgesellschaft $\mathrm{mBH}$ and New York: VCH Publishers Inc.) Vol. 2B, p. 351

Dayananda M A 1996 Metall. Mater. Trans. A27 2504

Goessmann F and Schmid-Fetzer R 1995 Mater. Sci. Engg. B34 224

Heanley J A and Dayananda M A 1986 Metall. Trans. A17 693

Heinrich K F J and Newbury D E 1991 Electron probe quantitative analysis (New York and London: Plenum Press)

Heumann Th 1962 Phys. Chem. 20168

Hirano K and lijima Y 1984 Diffusion in solids-Recent developments (eds) M A Dayananda and G E Murch (Detroit, Michigan: TMS-AIME) p. 141

Johnson W L 1986 Prog. Mater. Sci. 3081

Kale G B 1995 Advances in physical metallurgy (eds) S Banerjee and R V Ramanujam (New York: Gordon \& Beach) p. 299

Kale G B and Patil R V 1994 Mater. Trans. JIM 35439

Kale G B, Khera S K and Tiwari G P 1980 Titanium Sci. \& Technol. 80549

Kale G B, Bhanumurthy K, Khera S K and Asundi M K 1991 Metal. Trans. JIM 321034

Kale G B, Patil R V and Gawde P S 1998 J. Nucl. Mater. 25744

Kao C R and Chang A Y 1993 Acta Metall. 413463

Kucera J, Million B, Rek A and Stranskey K 1994 Matching welds (eds) $\mathrm{K} \mathrm{H}$ Schwalbe and $\mathrm{M}$ Kocak (London: ESIS Pub) p. 685

Matano C 1933 Jap. J. Phys. 8109

Onsagar L 1945 Ann. N.Y. Acad. Sci. 46241

Philibert J 1989 Defect \& Diffusion Forum 66-69 529

Philibert J 1997 Defect \& Diffusion Forum 143-147 529

Pretorious R, Marais T K and Therno C R 1993 Mater. Sci. Eng. 101

Sauer F and Frecise V 1962 Electrochemistry 66353

Van Loo F J J 1990 Prog. Solid State Chem. 2047

Wagner C 1969 Acta Metall. 1799

Walser R W and Bene R W 1976 Appl. Phys. Lett. 28624 